\title{
Molecular Taxonomic Studies of Actinomyces-Like Bacteria Isolated from Purulent Lesions in Pigs and Description of Actinomyces hyovaginalis sp. nov.
}

\author{
M. D. COLLINS, ${ }^{1 *}$ S. STUBBS, ${ }^{1}$ J. HOMMEZ, ${ }^{2}$ AND L. A. DEVRIESE ${ }^{3}$ \\ Department of Microbiology, AFRC Institute of Food Research, Reading Laboratory, Reading RG6 2EF, \\ United Kingdom, ${ }^{1}$ and Regional Veterinary Investigation Centre, Tochout, ${ }^{2}$ and Rijksuniversiteit Gent, \\ B-9000 Ghent, ${ }^{3}$ Belgium
}

\begin{abstract}
The 16S rRNA gene sequence of some Actinomyces-like bacteria isolated from purulent lesions in pigs was determined. A comparative analysis of the rRNA sequence data revealed that the bacteria are members of the genus Actinomyces, but are phylogenetically distinct from Actinomyces suis. On the basis of our findings and the results of previous phenotypic studies it is formally proposed that the bacteria from pigs should be designated a new species, Actinomyces hyovaginalis.
\end{abstract}

\begin{abstract}
During the course of a study of Actinomyces-like bacteria isolated from purulent lesions in pigs, two groups of organisms of uncertain taxonomic position were isolated (6). One of these groups, containing organisms isolated exclusively from purulent vaginal discharge and aborted fetuses, phenotypically resembled "Actinomyces suis", which was originally described by Franke (5). " $A$. suis" (Franke) was listed as a species incertae sedis in Bergey's Manual of Systematic Bacteriology (12) as no type strain exists for this species. Recently, Ludwig et al. (9) proposed that the pig pathogen Eubacterium suis (14) should be transferred to the genus Actinomyces as Actinomyces suis comb. nov. Phenotypically, this organism differs markedly from the description of " $A$. suis" published by Franke and from the unknown porcine isolates (6). In this study we determined the $16 S$ rRNA gene sequence of the unknown Actinomyces-like pig bacteria (6) in order to determine the precise phylogenetic position of these organisms.
\end{abstract}

\section{MATERIALS AND METHODS}

Cultivation. Strains were grown in Todd-Hewitt broth (Oxoid) supplemented with $5 \%$ sterile horse serum at $37^{\circ} \mathrm{C}$. Cultures were harvested at the late exponential phase by centrifugation.

Sequence determination of rRNA genes. Chromosomal DNA was isolated from wet packed cells as described by Pitcher et al. (10). The 16S rRNA gene was amplified by using a polymerase chain reaction and universal primers $\mathrm{pA}$ and $\mathrm{pH}^{*}(1)$. Approximately $2 \mu \mathrm{g}$ of chromosomal DNA was amplified in a total volume of $100 \mu$ l containing $2 \mathrm{U}$ of Taq polymerase (Amersham). The reaction involved 36 cycles consisting of denaturation at $92^{\circ} \mathrm{C}$ for $2 \mathrm{~min}$, primer annealing at $55^{\circ} \mathrm{C}$ for $1 \mathrm{~min}$, and primer extension at $72^{\circ} \mathrm{C}$ for 1.5 min. DNA was extracted with chloroform and purified by using a GeneClean II kit (Bio 101) according to the manufacturer's instructions. A qualitative analysis of the DNA fragments was performed by agarose gel electrophoresis. Sequencing of the amplified product was performed by using $\alpha-{ }^{35}$ S-dATP and a Sequenase version 2.0 sequencing kit (United States Biochemical Corp.) as described by Hutson et al. (8). Reaction products were separated on $55-\mathrm{cm}$

\footnotetext{
* Corresponding author.
}

wedge-shaped $(0.2$ to $0.6 \mathrm{~mm}) 6 \%$ acrylamide-7 M urea gels at $55^{\circ} \mathrm{C}$ by using an LKB Macrophor 2010 sequencing unit operated at $50 \mathrm{~W}$ per gel.

Analysis of sequence data. The sequences generated were aligned with other Actinomyces sequences $(9,13)$, and similarity values were determined by using the Beckman Microgenie program (11). Evolutionary distance values $\left(K_{\text {nuc }}\right)$ were calculated $(7)$, and an unrooted phylogenetic tree was constructed by using the distance matrix method (3, 4).

Nucleotide sequence accession number. The nucleotide sequence of the 16S rRNA of strain BM $1192 / 5^{\mathrm{T}}(\mathrm{T}=$ type strain) has been deposited in the GenBank (EMBL) data base under accession number X69616.

\section{RESULTS AND DISCUSSION}

The 16S rRNA gene of porcine isolate BM $1192 / 5^{\mathrm{T}}$ was amplified in vitro, and its nucleotide sequence was determined directly (8). The derived $16 \mathrm{~S}$ rRNA primary structure is shown in Fig. 1. The sequence consisted of 1,496 nucleotides (ranging from position 30 to position 1542; Escherichia coli numbering [2]). The sequence of a short fragment (ca. position 50 to position 450, which includes variable regions $V 1$ and $V 2$ ) of the $16 \mathrm{~S}$ rRNA of a second porcine isolate (strain BM753/6) was also determined. This sequence was found to be identical to the sequence of strain BM $1192 / 5^{\mathrm{T}}$, confirming the genetic homogeneity of the group II porcine isolates of Hommez et al. (6). The sequence of strain BM $1192 / 5^{\mathrm{T}}$ was compared with a data set containing more than 50 16S rRNA sequences of high-G+C-content gram-positive bacteria. The highest levels of 16S rRNA sequence similarity were with members of the genus Actinomyces. The similarity values for a ca. 1,332-nucleotide region (ranging from position 107 to position 1464 [Escherichia coli numbering system]) of the strain $\mathrm{BM} 1192 / 5^{\mathrm{T}}$ sequence and the sequences of previously described Actinomyces species are shown in Table 1. Approximately 100 nucleotides at the $5^{\prime}$ end of the rRNA were not included in these similarity calculations because of incomplete sequence data for some reference Actinomyces species. The closest relative of the porcine isolate was Actinomyces odontolyticus, which exhibited a 16S rRNA similarity value of ca. $95 \%$. Considerably lower similarity values were observed with other Actinomyces species (ca. 89 to $91 \%$ ). A phylogenetic 


\begin{abstract}
CGAACGCTGGCGGCGTGCTTAACACATGCAAGTCGAACGCACGGCCTIGGGGTITTCCTTGGGGTTGGTGAGTGGCGAACGGGTGAGTAACACGTGAGTA ACCTNCCCTCTTCTTTGGGATAACGGTCGGAAACGGNTGCTAATACTGGATATTCACACATTGTCGCATGGTGGTGTGTGGAAAGGTTTTITCTGGTGGG GGATGGGCTCGCGGCCTATCAGCTTGTTGGTGGGGTGATGGCTTACCAAGGCTTTGACGGGTAACCGGCCTGAGAGGGTGACCGGTCACATTGGGACT GA GATACGGCCCAGACTCCTACGGGAGGCAGCAGTGGGGAATTTTGCACAATGGACGGAAGTCTGATGCAGCGACGCCGCGTGAGGGATGGAGGCCTTCGGG TIGTGAACCTCTTTCGCTCATGGTCAAGCCGCAGCTTTGGGTTGTGGTGAGGGTAGTGGGTAAAGAAGCGCCGGCTAACTACGTGCCAGCAGCCGCGGTA ATACGTAGGGCGCGANCGTTGTCCGGAATTATTGGGCGTAAAGGGCTTGTAGGCGGTTGGTTGCGTCTGCCGTGAAAATCCTCTGGCTTAACTGGGGGCG TGCGGTGGGTACGGCCTGGCTTGAGTGCGGTAGGGGAGACTGGAATTCCTGGTGTAGCGGT GGAATGCGCAGATATCAGGAGGAACACCGGTGGCGAAGG CGGGTCTCTGGCCCGTTACTGACGCT GAGGAGCGAAAGCGTGGGGAGCGAACAGGATTAGATACCCTGGTAGTCCATNCTGTAAACGT TGGGCACTAGGT GTGGGGGCCACCCGTGGTT TCCTGCGCCGTAGCTAACGCTTTAAGTNCCCCGCCTGGGGAGTACGGCCGCAAGGCTAAAACTCAAAGGAATTGACGGGGG CCCGCACAAGCGGCGGAGCATGCGGATTAATTCGATGCAACGCGAAGAACCTTACCAAGGCT TGACATGCACCCAGAGCCTCCAGAGATGGGGGTGCATT TGGTTGGGGGTGTGCAGGTGGTGCATGGTTGTCGTCAGCTCGTGTCGTGAGATGTTGGGTAAGTCCCGCAACGAGCGCAACCCTTGCCCTATGTTGCCAG CACGTTGTGGTGGGGACTCGTGGGGGACTGCCGGGGTTAACTCGGAGGAAGGTGGGGATGACGTCAAATCATCATGCCCCTTATGTCTAGGGCTTCACGC ATGCTACAATGGCTGGTACAGAGGGTTGCGATGCTGTGAGGCGGAGCGAATCCCTTAAAGCTGGTCTCAGTTCGGATCGAAGTCTGCAACTCGACTTCGT GAAGGTGGAGTCGCTAGTAATCGCAGATCAGCAACGCTGCGGTGAATACGTTCTCGGGCCTTGTACACACCGCCCGTCACGTCACGAAAGTTGGTAACAC CCGAAGCNCATGGCCTAACCGGTTITCCGGGGNGAGTGGTCGAAGGTGGGATTGGCGATTGGGACGAAGTCGTAACAAGGTAGCCGTACCGGAAGG
\end{abstract}

FIG. 1. Nucleotide sequence of derived 16S rRNA of $A$. hyovaginalis.

tree depicting the interspecific relationships of the porcine isolate and other Actinomyces species is shown in Fig. 2.

A comparative $16 \mathrm{~S}$ rRNA sequence analysis clearly showed that the unknown bacterium is a member of the genus Actinomyces. The sequence analysis results demonstrated that the porcine bacterium and Actinomyces pyogenes, which also occurs in pigs, are genealogically only remotely related. The two groups differ in a large number of phenotypic characteristics (6). It was also evident from this analysis that the unknown Actinomyces taxon is genotypically distinct from the porcine pathogen designated $A$. suis (formerly Eubacterium suis) by Ludwig et al. (9). The unknown porcine isolates differ from $A$. suis as described by Ludwig et al. (9) in producing acid from L-arabinose, salicin, sucrose, D-xylose, D-mannose, and D-fructose. The unknown bacterium also differs from $A$. suis in hydrolyzing esculin, reducing nitrate, and not having urease activity. In view of the phenotypic and phylogenetic distinctiveness of the porcine bacterium, a new species, Actinomyces hyovaginalis, is proposed for this organism.

Description of Actinomyces hyovaginalis sp. nov. Actinomyces hyovaginalis (hy.o.va.gi.na'lis. Gr. n. hys, pig; L. n. vagina, sheath, vagina; N. L. masc. adj. hyovaginalis, pertaining to the vagina of a pig). The following morphological and physiological description is based on a study of 14 strains (6).

The cells are predominantly diptheroidal, and the rods are arranged in clusters or V or Y forms; coccoid elements may

TABLE 1. Levels of 16S rRNA sequence similarity between A. hyovaginalis, some other Actinomyces species, and Bifidobacterium bifidum

\begin{tabular}{|c|c|c|c|c|c|c|c|}
\hline \multirow[b]{2}{*}{ Species } & \multicolumn{7}{|c|}{$\%$ 16S rRNA sequence similarity with ${ }^{a}$ : } \\
\hline & 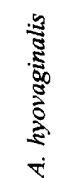 & $\begin{array}{l}\frac{3}{3} \\
8 \\
8\end{array}$ & 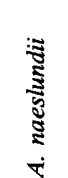 & 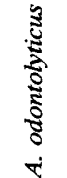 & 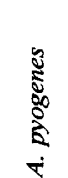 & 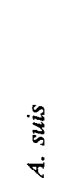 & 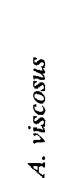 \\
\hline A. bovis & 90.7 & & & & & & \\
\hline A. naeslundii & 89.7 & 94.1 & & & & & \\
\hline A. odontolyticus & 94.9 & 91.6 & 90.4 & & & & \\
\hline A. pyogenes & 88.9 & 88.1 & 87.1 & 88.7 & & & \\
\hline A. suis & 89.0 & 87.5 & 86.9 & 88.1 & 91.0 & & \\
\hline A. viscosus & 90.4 & 94.5 & 96.8 & 91.5 & 88.1 & 87.8 & \\
\hline Bifidobacterium bifidum & 85.1 & 85.4 & 84.4 & 85.6 & 84.5 & 83.6 & 85.1 \\
\hline
\end{tabular}

\footnotetext{
${ }^{a}$ Similarity values are based on a comparison of ca. 1,332 nucleotides.
}

occur. Colonies are flat with outrunning edges, a trait which is particularly pronounced after anaerobic incubation or incubation under $\mathrm{CO}_{2}$ on horse blood agar. Nonhemolytic. Catalase negative. Acid is produced from adonitol, L- and $\mathrm{D}$-arabinose, $N$-acetylglucosamine, L-arabitol, galactose, glucose, gluconate, fructose, D-mannose, maltose, D-lyxose, salicin, sucrose, turanose, and D-xylose. Some strains produce acid from cellobiose, inositol, lactose, and $\beta$-methylxyloside. Acid is not produced from D-arabitol, dulcitol, $\alpha$-methyl-D-glucoside, $\beta$-gentiobiose, inulin, melezitose, melibiose, raffinose, rhamnose, sorbitol, D-tagatose, trehalose, L-xylose, and xylitol. Alkaline phosphatase, $\alpha$-galacto-

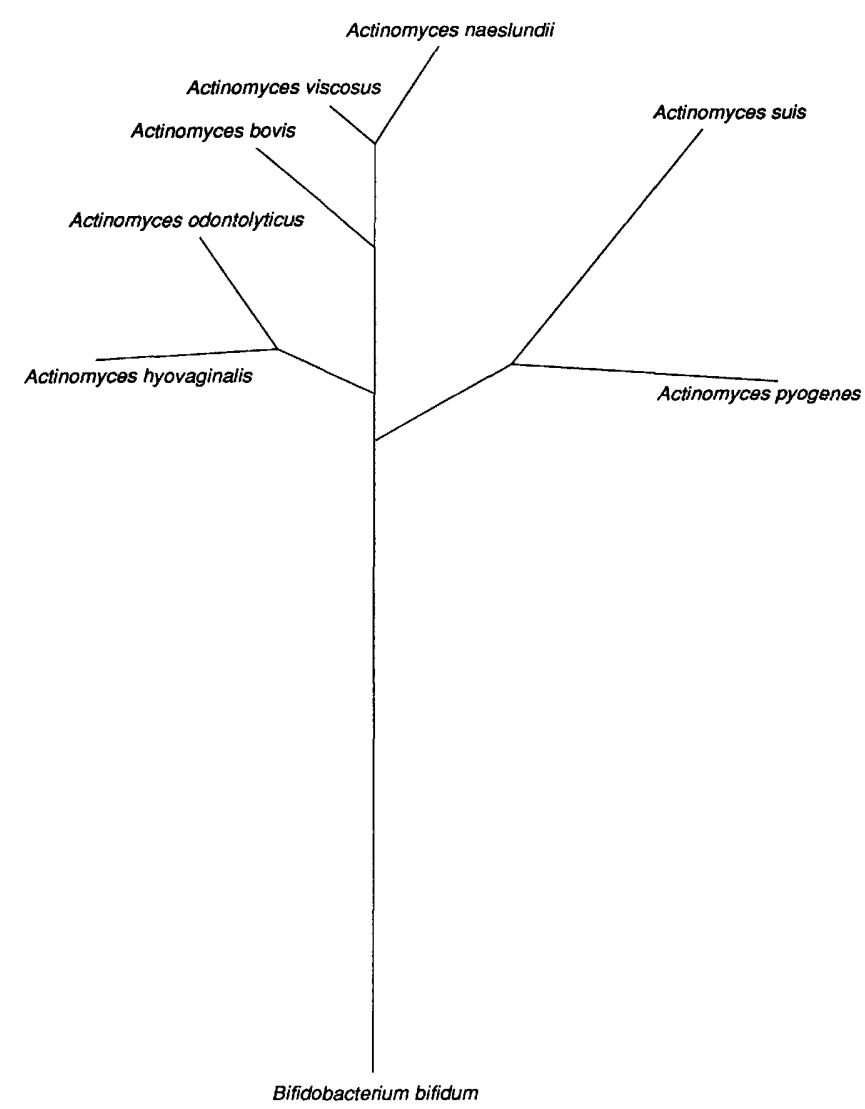

FIG. 2. Unrooted tree showing the phylogenetic interrelationships of $A$. hyovaginalis and some other Actinomyces species. The tree is based on a comparison of ca. 1,332 nucleotides. 
sidase, $\beta$-galactosidase, and leucine arylamidase positive. Pyrrolidonylarylamidase, pyrazinamidase, and $\beta$-glucuronidase negative. Esculin, hippurate, and Tween 80 are hydrolyzed. Arginine, gelatin, and urea are not hydrolyzed. Nitrate is reduced to nitrite. The cell wall murein type is type A5 $\beta$ (Orn-Lys-Glu). The DNA base composition is $63 \mathrm{~mol} \%$ $\mathrm{G}+\mathrm{C}$ (as determined by the thermal denaturation method). The type strain is strain NCFB 2983 (= BM 1192/5). The habitat is the porcine genital tract.

\section{ACKNOWLEDGMENTS}

We are grateful to $\mathrm{N}$. Weiss (Deutsche Sammlung von Mikroorganismen, Braunschweig, Germany) for providing cell wall murein data and T. O. MacAdoo (Virginia Polytechnic Institute and State University, Blacksburg), for deriving the species name.

We thank the EEC (HRAMI project BIOT-CT-91-0294SSMA) for support.

\section{REFERENCES}

1. Boddinghaus, B., J. Wolters, W. Heikens, and E. C. Bottger. 1990. Phylogenetic analysis and identification of six different serovars of Mycobacterium intracellulare at the molecular level. FEMS Microbiol. Lett. 70:197-204.

2. Brosius, J., M. L. Palmer, P. J. Kennedy, and H. F. Noller. 1978. Complete nucleotide sequence of a 16S ribosomal RNA gene from Escherichia coli. Proc. Natl. Acad. Sci. USA 75:48014805.

3. Felsenstein, L. 1982. Numerical methods for inferring evolutionary trees. Q. Rev. Biol. 57:379-404.

4. Fitch, W. M., and E. Margoliash. 1967. Construction of phylogenetic trees: a method based on mutation distances as estimated from cytochrome $\mathrm{c}$ sequences is of general applicability. Science 155:279-284.

5. Franke, F. 1973. Untersuchungen zur Ätiologie der Gesäugeak- tinomykose des Schweines. Zentralbl. Bakteriol. Parasitenkd. Infektionskr. Hyg. Abt. 1 Orig. Reihe A 223:111-124.

6. Hommez, J., L. A. Devriese, C. Miry, and F. Castryck. 1991. Characterization of 2 groups of Actinomyces-like bacteria isolated from purulent lesions in pigs. J. Vet. Med. Ser. B 38:575-580.

7. Hori, H., and S. Osawa. 1979. Evolutionary change in 5S rRNA secondary structure and phylogenetic tree of 54 5S rRNA species. Proc. Natl. Acad. Sci. USA 76:381-385.

8. Hutson, R. A., D. E. Thompson, and M. D. Collins. 1993. Genetic interrelationships of saccharolytic Clostridium botulinum types $\mathrm{B}, \mathrm{E}$ and $\mathrm{F}$ and related clostridia as revealed by small-subunit rRNA gene sequences. FEMS Microbiol. Lett. 108:103-110.

9. Ludwig, W., G. Kirchhoff, M. Weizenegger, and N. Weiss. 1992. Phylogenetic evidence for the transfer of Eubacterium suis to the genus Actinomyces as Actinomyces suis comb. nov. Int. J. Syst. Bacteriol. 42:161-165.

10. Pitcher, D. G., N. A. Saunders, and R. J. Owen. 1989. Rapid extraction of bacterial genomic DNA with guanidium thiocyanate. Lett. Appl. Microbiol. 8:151-156.

11. Queen, C., and L. J. Korn. 1984. A comprehensive sequence analysis program for the IBM personal computer. Nucleic Acids Res. 12:581-599.

12. Schaal, K. P. Genus Actinomyces, p. 1383-1418. In P. H. A. Sneath, N. S. Mair, M. E. Sharpe, and J. G. Holt (ed.), Bergey's manual of systematic bacteriology, vol. 2. The Williams \& Wilkins Co., Baltimore.

13. Stackebrandt, E., and O. Charfreitag. 1990. Partial 16S rRNA primary structure of five Actinomyces species: phylogenetic implications and development of an Actinomyces israeliispecific oligonucleotide probe. J. Gen. Microbiol. 136:37-43.

14. Wegienek, J., and C. A. Reddy. 1982. Taxonomic study of "Corynebacterium suis" Soltys and Spratling: proposal of Eubacterium suis (nom. rev.) comb. nov. Int. J. Syst. Bacteriol. 32:218-228. 